\title{
INDIVIDUAL TESTS OF SCHOOL CHILDREN.
}

\author{
BY E. A. KIRKPATRICK.
}

In connection with tests made upon about five hundred school children to determine defects of sight and hearing, I made a few other tests that may be of interest to this Association, which has devoted considerable time and some money to formulating a series of individual tests for college and university students, with the idea that a test of ability, better than an examination test, or supplementary to such a test, may be found. Such a test is needed more for public school children than for College students, and it is reasonable to suppose that accuracy and rapidity in the simple sensory and motor activities would be a better indication of general ability in school children than in College students, whose activities are more complex and less concerned with simple sensory and motor operations. The results of the preliminary tests thus far made, which are to be followed by others, are not conclusive, but only suggestive of what is required in the way of standards and of what may be hoped for in the future from such tests.

The tests used were: First, counting aloud as rapidly as possible for ten seconds. Second, making vertical marks as rapidly as possible for the same length of time. (The time it took the pupil to count the marks he had made was also recorded.) Third, sorting twenty-five cards into four piles according to oral directions by the numerals one, two, three and four. Fourth, sorting twenty-five cards into four piles according to visual impression, each card having on it one of the four letters A, B, C, or D. Fifth, naming four ink spots, about one minute being allowed in which to name them. Time was measured in all cases by means of a stop watch and each pupil was tested but once after a few preliminary tests, in which it was found that in most cases the time was not greatly different in the second test unless the experiment was misunderstood. All 
the tests were made by myself, hence the personal element which would be quite important in the oral card test and in giving directions was the same for all. A very few pupils who had just entered the first grade could not count far enough to consume the whole of the ten seconds. With very young children the mental element of association apparently determined the limit of rate, while for older pupils the rate of movement of the vocal organs seemed to fix the limit of speed. In the marking test the younger children were usually more careful as to how they made the marks than the older ones. In the card test also it was at first surprising to find that fewer mistakes were often made by the younger than by the older children, but observation showed that the younger children were likely to think more about the thing to be done and the older ones about doing it quickly, hence one took the sensory form of reaction while the other inclined toward the motor form and therefore sometimes made more mistakes.

More than half the children tested were American, though many other nationalities were represented. They all belonged to the model and practice schools of the Fitchburg Normal School, and at least one model school and one practice school are represented in each grade tabulated except in the second.

There were considerable differences both for individuals of the same room and for rooms of the same grade, but, in general, as is shown in the table, there was an improvement in the first four tests up to about the sixth or seventh grade, when it ceased or became slower or there was an actual decrease in rate.

In the fifth or ink spot test the younger children seemed more suggestible or imaginative, as they named more of the spots. The number who saw the spots as objects was less in the fourth, fifth and sixth grades, but increased in the seventh and eighth grades, though not equalling those of the first. The younger children seemed to have no doubt whatever of the spot being a picture of the object they named, while the older children simply said ' it is some like' or 'it looks a little like' 'a dog,' 'cloud' or whatever else was suggested. This supremacy of the small children is striking when we consider that 
the number of mental images that they have is much smaller than that possessed by older children, who may name a part of the body or the map of a country or something else that the younger children know nothing about.

TABle.

\begin{tabular}{|c|c|c|c|c|c|c|c|c|}
\hline GradE. & 1 & 2 & 3 & 4 & 5 & 6 & 7 & 8 \\
\hline $\begin{array}{l}\text { Number of children, } \\
\text { Average number counted, } \\
\text { Average number of marks made, } \\
\text { Time of sorting cards (oral), } \\
\text { Time of sorting cards (visual), } \\
\text { Pictures named, }\end{array}$ & $\begin{array}{l}36 . \\
25.8 \\
19.7 \\
52 . \\
61.4 \\
2.9\end{array}$ & $\begin{array}{l}16 \\
31 \\
28 \\
43 \\
40 \\
2.5\end{array}$ & $\mid \begin{array}{l}51 \\
31 \\
3.5 \\
49 \\
41 \\
2.6\end{array}$ & $\begin{array}{l}72 \\
34.5 \\
36.8 \\
35 \\
34 \\
1.8\end{array}$ & $\begin{array}{l}67 . \\
36.1 \\
38.8 \\
29 . \\
25 \cdot 3 \\
1.9\end{array}$ & $\begin{array}{l}35 . \\
45 \\
458 \\
31 \\
27.3 \\
1.7\end{array}$ & $\begin{array}{l}49 \\
40 \\
46 . \\
24.5 \\
23.6 \\
2.1\end{array}$ & $\begin{array}{l}55 . \\
37.8 \\
47 \cdot 4 \\
28 . \\
23 . \\
2.2\end{array}$ \\
\hline
\end{tabular}

The smaller number of objects seen in the spots by the children of the fourth, fifth and sixth grades is probably to be explained by the fact that children of those ages have become more critical in their sense perceptions as their ideas have become more definite and as they have learned from life's experiences and from training to be more careful in their judgments. The older pupils of the seventh and eighth grades, on the other hand, have passed into another stage in which they realize that a picture is not necessarily this or that, but may resemble any one of several things, hence they are not afraid to say what it looks like.

Most of those who named three or four of the spots named more than one object of a class, as two kinds of vegetables or two animals, showing that the presence of one idea of a group made others of that group more suggestible.

The results of the various tests were not tabulated according to age, but the averages of those who were much older and those much younger than the average of the room in each case were taken and found to differ somewhat from the general average of the room. In general, the pupils older than their grade were better in their tests in the lower grades and not so good in the higher grades, while younger pupils were better than their mates in the eighth grade and not so good in the lower grades. The two factors apparently determining the record a child makes are experience that comes with age, and ability. In the lower grades 
the experience that comes with age is more important than intellectual brightness and knowledge, while above the sixth or seventh grade, at which time the powers tested seem to reach their maximum, ability counts for more than age or both count in the same direction to increase the comparative record of bright young children who have been promoted with older pupils.

In order to determine the significance of these tests of individual pupils, the teachers were asked to grade the children into three classes according to ability as compared with their mates in the same room. In most cases the teachers could do this without much hesitation, though pupils who were good in some lines and poor in others and pupils who did not always try gave them some trouble. The children were graded by me according to the tests and the two gradings compared. A different standard was adopted for each room for each test except for the ink spots and the perfectness of execution in making lines and sorting cards without mistake, in which cases the standards were the same for all grades. For the average grade of ability a standard was adopted with such a maximum and such a minimum above and below the mean or average for children of the same room and sex, that half, or a little more, of the children would be in the average class, while approximately one-fourth were in each of the two classes above and below the average. The teachers' gradings were compared with the grading according to the counting and marking test combined, compared with those of the two card sorting tests combined and finally compared with all the tests combined. The percentage of correspondence did not differ greatly in the different comparisons, but was a little greater for all the tests than for part of them. Fifty-seven per cent. were graded just the same by the combination of all the tests as by the teacher, while only two per cent. were placed in the class farthest removed from that in which they were placed by the teacher. This is probably as close a correspondence as would obtain between the judgments of two different teachers, which indicates that such tests would be likely to be of some value to superintendents in settling doubtful cases of promotion.

Where the results of the tests are directly opposed to the 
teacher's judgment of a pupil we cannot say which is most nearly correct, but the following principles should be considered. In general, average size or ability in vegetables, animals and men is regarded with more favor when it is a question of selecting for breeding purposes or for positions of responsibility. Unusual development in one direction is to some extent abnormal and often associated with some weakness in other directions. For this reason a good average in such a test is probably as good an indication of good general ability as a record very much above the average. On the other hand one who is much below the average is not only abnormal, but abnormal in the wrong way, and hence cannot be expected to have good general ability. A poor pupil may, therefore, make either a very high or a very low or even an average record in such a test, but a very good pupil is not likely to make a very low record, though he may make only an average one.

One result of this experiment suggests possibilities, and, to my mind, probabilities of the greatest importance in establishing standards for testing individuals of different ages and in determining the best kind of tests to be used for any age. I refer to the fact that in most of the experiments pupils of the eighth grade made little or no better record than those of the sixth and seventh and sometimes not so good a record. Wolfe noted a similar fact in his experiments in that the pupils of the eighth grade judged size and weight more accurately than university students. Bentley also found more improvement in rate of naming words or letters than in naming colors or pictures, while Gilbert in his numerous experiments upon school children found that the rate of improvement in different lines was not the same at different ages We know also that, according to the general laws of habit, improvement becomes slower with practice as the limit of possible improvement is reached. The experiences of every-day life and the school training received by all probably mature some powers before there is occasion to exercise others a great deal. Again, all child study investigations indicate that there are inner laws of development which cause certain activities to become prominent and develop almost to maturity before others have scarcely begun, with almost as much certainty as 
the flower of a plant becomes perfect before the fruit begins to form. This inner tendency of development which recapitulates in part at least the history of the race is the principal influence in determining the direction of activity, while the opportunity for practice and laws of habit determine the extent to which the powers are developed. This view being accepted, it seems altogether probable that we are wrong in assuming that increased age should show increased power in elementary activities, and that superiority of one adult to others in these activities is an indication of greater mental ability. In children the possession of great sensory and motor power may be the best indication of general mental ability, but it may be that such superiority in adults should in some instances be interpreted as a sign of arrested development, for the adult who is still developing his sensory and motor activity is perhaps quite inferior to the one who has ceased to develop in those lines, but is now gaining in power of abstraction and reasoning. Good answers to questions calling for facts of general and incidental observation, such as " How many wings has a fly?" "Which way do the seeds of an apple point?" "How many windows are there in a well-known room $r$ " and others like them asked by Professor Cattell may indicate, not so much alertness and mental ability as diffused attention and lack of the power that goes with concentrated and selective attention. We cannot tell a priori what good records in the various tests that we apply mean. It may mean that the individual is superior to his fellows of the same age in activities naturally prominent at that age, and hence probably superior in general ability, or it may mean that he has not yet begun to develop along new and higher lines that are appropriate to his age and that are now absorbing the attention of his fellows.

I wish to emphasize to this Association the importance of testing persons of different ages and seeking for the normal standard at each age before we can intelligently interpret individual records. The psychological problem of tests of general mental ability cannot be solved till the psychogenetic problem of the stages of improvement in the various lines of mental development has been solved. In my judgment the results of the tests that have been made for several years upon the entering 
students of several universities will be valuable in determining normal standards for the ages and sexes tested, but they cannot be interpreted as measures of general intellectual development and ability till the same tests have been made upon children of different ages.

In conclusion, I would suggest that it is desirable to have tests of such a nature that they can be taken by children as well as adults, that they shall be such that all persons tested will have had about equal opportunity for the exercise of the power tested, and that in the interest of economy of time the tests so far as possible shall be so planned that they can be given to a whole class or school at once, instead of to each individual separately. 